\title{
Research on Subjective Well- being of College Students and Its Major Factors
}

\author{
Fei Wang \\ Wenshan University, Wenshan, 663000, China
}

Keywords: Subjective well- being, College students, Major factors

\begin{abstract}
The subjective well-being of college students reflects their quality of life, and has a positive impact on their physical and mental health, their growth and development. It is of great significance to study the subjective well-being of college students. This paper analyzes the two main factors affecting subjective well-being of college students: desire and incidents. To cultivate humanity quality, strengthen social support, adjust expected levels can enhance the subjective wellbeing of college students.
\end{abstract}

\section{Introduction}

Subjective well- being consists of two main components: emotional component and cognitive component. The emotion component is the emotion experience which the individual feels in the real life, divides into the positive emotion and the negative emotion. Positive emotions include emotional experiences such as pleasure, joy, interest. Negative emotions are experiences of worry, depression, sadness. Individuals who experience more positive emotions and less negative emotions are undoubtedly happier. Cognitive component refers to the cognitive assessment of life quality, that is, life satisfaction, including overall life satisfaction and life satisfaction in specific domains, such as work, marriage, health and so on. Satisfaction in specific domains has an important influence on overall well-being. Although people use self-determination criteria in their satisfaction assessment, it is certain that subjective well-being of individuals who are satisfied with the key aspects of life and life in general is higher. Different cultural backgrounds and age groups have different focuses, and the content of specific areas that can affect happiness also has its particularity. It is necessary to study them separately. The structure of subjective well-being has been supported by many researchers. Life satisfaction, as a cognitive component of subjective well-being, constitutes an independent dimension, which is distinguished from positive emotion and negative emotion. At the same time, positive emotions and negative emotions are independent of each other, not one dimensional bipolar. The score of positive emotion does not necessarily mean the score of negative emotion, and the correlation degree between different variables is different, so it is necessary to study positive emotion and negative emotion at the same time. This article regards this as its theoretical support. The subjective well-being of college students is defined as the overall evaluation of the quality of life of college students according to their own standards". Respect the self-evaluation of college students, investigate their own views and feelings about happiness, carry out project collection, and explore the structure and characteristics of College Students' subjective well-being.

\section{Major Factors of Subjective Well- being of College Students}

Desire. There are many human desires, and the specific college students, academic achievement is an important part of their desire, this section focuses on the subjective well-being of college students and academic achievement related. Boys' academic achievement is more dependent on internal control than girls', but the differences between the two are not obvious, which have long been confirmed in previous studies. In the study, we can see that since the internal control ability of the only child is better than that of the non-only child, the scores of the only child in academic 
achievement are higher than those of the non-only child, but the difference is not obvious. In a sense, these are because the only child has a more favorable psychological quality.

Table 1. Relationship between subjective well-being and desire

\begin{tabular}{|l|r|l|}
\hline & Subjective well-being & Desire \\
\hline Subjective well-being & -0.83 & \\
\hline Desire & -0. \\
\hline
\end{tabular}

$\mathrm{N}=268,{ }^{*} \mathrm{p}<0.05$

According to the scholars, the only child is superior to the non-only child in many aspects. These aspects include intelligence and achievement, control, autonomy, leadership, and psychological maturity. As the only child grows up in the doting parents, the exclusive possession of the family resources leads to the self-centered role of the only child, this problem is mentioned in many references in the literature. Research shows that the subjective well-being of male and female students is basically the same, boys slightly higher, but the difference is not obvious. This is consistent with some previous studies. From these studies, there is no significant difference between male and female students in subjective well-being. In other words, gender has nothing to do with subjective well-being. This subtle difference is caused by the sampling process, also may be since with the reform and development for decades, China's productivity has been rapid development, people's thinking has also been the development of college students is an active community, received a lot of new ideas, so it reduces the gender differences in the original. In conclusion, gender has a negligible effect on subjective well-being, so it can be ignored. The author summarizes and Study on the relation between desire and subjective well-being, initially feel unable to start, because it contains too much, after careful thinking, I suddenly found that for college students, then grasp the characteristics of this group, it is not difficult to find, as a student. As a college student, they desire the most important is the nature of academic achievement.

Incidents. The subjective well-being of the students compared with other students, each factor reflects the subjective well-being scores were in the middle level, the factors including subjective well-being, family satisfaction, classmate's friend's satisfaction, positive emotion, environment satisfaction, emotional satisfaction, negative emotion, learning and self-satisfaction, higher scores. From the statistical point of view to analyze the situation of higher vocational college students, male and female students' subjective well-being, the gender difference is mainly manifested in two aspects: first, the total scores of vocational colleges female student's subjective well-being is higher than the total average of college Students' subjective well-being of the male, two, female vocational college students' subjective well-being scores.

Table 2. Relationship between subjective well-being and incident

\begin{tabular}{|l|r|l|}
\hline & Subjective well-being & Incident \\
\hline Subjective well-being & & \\
\hline Incident & 0.73 & \\
\hline $\mathrm{N}=223,{ }^{*} \mathrm{P}<0.05$ &
\end{tabular}

Considering family satisfaction factors and emotional satisfaction factors, the scores of subjective well-being of male college students were significantly higher than those of Higher Vocational College students. In other respects, there were no statistically significant differences in well-being between men and women. When we examined the scores of happiness scores from urban and rural students, we found that the two sets of data were not regularly searched, and the total scores were not statistically significant. We also made a questionnaire survey on the subjective well-being of college students of different majors and grades. From the questionnaire data, we can easily find that freshmen, grade two, grade three, grade four college students subjective well-being difference is statistically significant. In the four grade students, the highest score is the third-grade college students' subjective well-being, subjective well-being is the lowest score of the first-grade students, the scores of subjective well-being in the middle is the fourth grade and the second-grade college students. To 
further analyze the differences between, we compared multiple variance, found the first-grade students and other grade students is significantly different, while the second-grade students and the scores of other grades are not significant, meanwhile, scores of vocational college students of the third grade and the fourth grade is not obvious. In addition, the scores of liberal arts students are not very different from those of science students.

\section{Paths of Enhancing Subjective Well- being of College Students}

Cultivate Humanity Quality. Happiness needs education, but the current education utilitarian tendency is serious, the people as social development tools, the education to train people down to only master production skills and prepare for the occupation level. The education of knowledge become a dead dogma, teach students to instill the way, hinder the development of students' intelligence. Education is treated as a technical work, and the belief that education is superior, seeking elegance and seeking purity is gradually lost. From the current situation, the quality of the students is worrying, the weak culture influences the students' humanistic quality and ideology is not enough, because of not paying attention to the ideological cultivation, their ideas are often not from the top of the doctrine of very strange thinkers always and in all countries. And happy life needs the guidance of the light of wisdom to get it. The wisdom of our forefathers can provide us with a new idea or new angle of view to understand life. Without wisdom, no man could live a happy life. Compared with happier people, they reduce their subjective well-being and improve their subjective well-being compared to those who are less fortunate. The adaptation theory is a longitudinal comparison, which means that life is better now than it used to be. Wisdom is marked by joy, joy, happiness, joy. Therefore, if college students want to improve their subjective well-being, they should actively study their predecessors' wisdom and try hard to improve their humanistic quality. Humanistic quality makes people understand the existence, value and realm of human beings. The quality of humanities directly determines the level of people's moral civilization, which directly determines the real grasp of happiness. The literary beauty, people can be more vivid and more realistic understanding of happiness, understanding the meaning of happiness; history gives people the lofty sense of mission, let people pursue happiness in the history of the pulse; make a thorough understanding of philosophical wisdom, let people in the changing current of the times grasp the true happiness in life, to achieve guide the life perfect, which should be an important content of the humanistic quality education.

Strengthen Social Support. Family emotional support and classmates and friends are the most important reasons for college students' happiness, and they are also the major causes of College Students' unhappiness. The confusion and discomfort in college students' interpersonal relationships are mainly as follows: lack of intimate friends; difficulty in meeting with other people; plain association with others; difficulty in communication; even fear of communication and avoidance of communication. According to the current prevalence of interpersonal problems in college students, I think we can take some measures or methods to alleviate or relieve these problems, summed up in the following strategies: modest and prudent position. Take college life as a new starting point, look at the people and things around you calmly, maintain a peaceful and rational attitude, and treat people with humility. Therefore, college students can actively engage in these activities they enjoy, so that their positive emotions continue to increase. Especially when you are in a negative mood, be conscious of what you can do to cheer yourself up. For example, many college students have the experience, when depressed, and the students hit a ball, a sweat, and then come back to take a bath, the mood will feel more comfortable. Although only truth everyone understands, but because some students can't overcome their inertia, and cannot stick or not often engage in this help to enhance their positive emotional activities, it is important that the students should have a sense of initiative. Treat each other as equals and get along in good faith. Goodness, honesty, sincere praise and criticism can make mutual understanding and trust, and willing to talk. Active opening. Only by opening your heart and showing your heart can you walk into someone else's heart and others will respond to you with a frank and friendly gesture. Psychological exchange and compatibility. When you stand in other 
people's position and look at the problem, you will understand what other people say and do, and get a lot of understanding that you have never had before, and you will feel that the psychological distance is shortened.

Adjust Expected Levels. Individuals have a greater influence on their expectations and subjective well-being. According to the theory of expectancy value of subjective well-being, when individuals evaluate subjective well-being, they are always compared with certain standards. In fact, this standard is the expected goal of an individual. If the goal is achieved, the subjective well-being is higher and the opposite is low. But in fact, high expectations are bad for personal satisfaction. High expectations are an important threat to happiness. Expectation value is not the best predictor of subjective well-being, while expectations, actual conditions, and external and intrinsic resources can be used as predictors of subjective well-being. Subjective well-being reflects the "gap" between individual expectations and achievement levels". Gap refers to the difference between the expected value of an individual and the level of achievement. Expectations tend to be higher than achievement levels. The smaller the difference between the two, the happier the individual is, the gap between zero, high levels of happiness, higher levels of achievement than expected, and a high level of subjective well-being. For today's college students, the gap between reality and ideal makes some college students have a strong psychological gap, which seriously threatens their happiness. Influenced by society and family, college students generally expect higher self. When they cannot achieve the desired goal or not fully affirmed by others, it is prone to psychological confusion, and even psychological illness. This study shows that, since entering college lower happiness college students said that most college life and their expectations are not consistent in this study also showed that for the future of the concern is an important cause of college students are not happy, many college students in the questionnaire indicated that the gap between ideal and reality so that they are not happy. As students of the life expectancy is relatively high, that their study with more than ten years, and spent so much tuition, the society should give yourself rewards. Therefore, for college students, we should learn to adjust their expectations, establish their own goals and narrow the gap between their own conditions and their ideal goals.

\section{Conclusion}

The research on subjective well-being of college students started late in our country, and there are few studies on the subjective well-being of College students. At present, most researchers use foreign existing scales to measure subjective well-being of college students, and lack a scale with high reliability and validity, which is specifically compiled for Chinese College students.

\section{References}

[1] Cao Yi, Li Weiqiang, Zhang Ying. Research of College Student Social Development and Subjective Well-Being [J]. China Journal of Health Psychology, 2015, 23(1): 109-112.

[2] Liu Li, Bi Xiaohui, Wang Meifang. College Students' Social Support and Subjective Well-being: The Mediating Role of Belief in Just World [J]. Chinese Journal of Clinical Psychology, 2015, 23(4): 715-717+721.

[3] Shen Qi, Liao Shengqing, Qin Yue. Internent Use, Social Support and Subject-Wellbing [J]. Journalism \& Communication, 2014(6): 99-113+128.

[4] Li Wenhua, Wang Liping, Yuan Jie. Correlation of Family Cohesion, Family Adaptability and Subjective Well- being in College Students [J]. China Journal of Health Psychology, 2014, 22(7): 1067-1070. 